\title{
Social-Professional Factors and Predominance of Burnout Syndrome in Tunisian Male Soccer Players
}

\author{
Majdi BOUAZIZI ${ }^{1}$, Maamer SLIMANI ${ }^{1}$, Sabri GAIED CHORTANE ${ }^{2}$, \\ and Foued CHEOUR ${ }^{3}$ \\ ${ }^{I}$ Faculty of Sciences of Bizerte, Tunisia \\ ${ }^{2}$ High Institute of Sport and Physical Education of Sfax, Tunisia \\ ${ }^{3}$ Thesis supervisor. High Institute of Applied Biology of Médenine, Tunisia
}

\begin{abstract}
The objective of this study was to evaluate the effects of certain social-professional factors on the burnout syndrome development among 132 Tunisian male soccer players $(24.34 \pm 5.55$ years, $70.42 \pm 7.9 \mathrm{~kg}$ and $1.76 \pm 0.06 \mathrm{~cm}$ ) belonging to the Tunisian Soccer League First Division. Our results have shown that Tunisian male soccer players are affected by burnout syndrome and the factors 'Player team integration', 'Player coach relationship', 'Player age', 'Player material conditions', 'Player seniority' significantly promote its trigger. These factors appear to be slightly different from those reported in other study carried out in United Kingdom on professional soccer players of the first division which specified that 'Player age', 'Player education level', 'Player physical condition', 'Player marital status', 'Player position' and 'Player seniority' are the main factors triggering burnout. The manifestation of the burnout in our study seems to be particularly the result of its three components' development, such as the emotional exhaustion, the deshumanization and the reduced personal accomplishment.
\end{abstract}

Keywords: Burnout; Social-professional factors; soccer players.

\section{Introduction}

Nowadays, different pressures experienced by the elite athletes during their practice are such that they have a physical, mental and emotional total commitment. Increasing pressure from coaches, executives, families, financial and media lead the elite athlete to a greater risk of experiencing, higher states of psychological fatigue, a progressive disgust, loss interest and motivation for sport etc., which may be finalized by a brutal and negative abandonment of the practice (Miller et al., 1990; Hentati et al., 2014).

Burnout is a clinical and psychopathological suffering increasingly evoked in our society. It is originally described as a reduction of resources, mental and physical progressively leading to professional and personal problems (Freudenberger et al., 1974). In addition, personal expectations and needs of individuals influence their occupational performances and daily lives. Burnout syndrome, which appears as the indicator of emotional, mental and physical weariness in individuals, has continued to be an important topic since it was revealed in the 1970's (Laes and Laes, 2001; Pines and Nunes, 2003). The expression of burnout was firstly used by a psychiatrist, Freudenberger. In the following years, it was also used by Maslach (Maslach et al., 2001). He defined burnout as the failure, and exhaustion of the person as a result of over-demand on energy, power and resources (Freudenberger, 1974). It is suggested that burnout is not a phenomenon restricted to certain types of jobs and burnout levels can be determined for all groups of jobs (Pines et al., 1981; Pines and Aronson, 1988). Early research on burnout focused on people with different professions (Maslach, 1982). But Pines (1993) expanded the concept of burnout and suggested that there is a risk of burnout in any situation where there is high for achievement motivation.

The burnout syndrome currently refers to a three-dimensional syndrome composed by an emotional exhaustion sense, a form of relational divestment-disengagement or depersonalization and finally a reduction sense of accomplishment or in the self-efficacy (Maslach and Schaufeli, 1993). Emotional exhaustion is characterized by a feeling of lack of energy and inability to provide assistance to others. The divestment resulted in a negative attitude towards others and detached progressing to a reification of the other. The third dimension of burnout reflects a decrease in the sense of accomplishment, the self-realization or the sense of personal and professional effectiveness. The individual will be a particularly negative and demeaning view of most of its achievements. This loss of confidence is associated with depression (Ahola et al., 2005). The model of the general adaptation syndrome describes three phases following exposure to stressors, namely, i.e the alarm, resistance and exhaustion. This model postulates a causal chain in which the experience of stress contributes to the burnout etiology. Generally refers to burnout after exposure to professional stress during periods ranging from one to five years (Canouï, 2001). 
Soccer is the most popular game in the world. FIFA lists 270 million practitioners, account 301,000 clubs, and 38,287,000 licensees of which 113,000 professional players. Soccer has the status of number one sport in most countries. Soccer has the status of number one sport in most countries. Some continents such as Africa, South America and Europe are even almost entirely dominated by this discipline. Soccer is a collective sport between two teams of eleven players on a field in a stadium. The objective of each course is to put a spherical ball into the goal without using arms, and do it more often than the other team (Guttman, 1993; Dunning, 1999). However, the mood of the players in this discipline, like all other professions, is often affected by social-professional factors such as age, education level, physical conditions, marital status, soccer seniority and soccer player position that can considerably influence the performance (Gumusdag et al., 2013).

The objective of this study was to evaluate the effects of certain socio-professional factors on the development of burnout syndrome in Tunisian male soccer players.

\section{Materials and methods}

\section{Soccer players}

This study was conducted on 132 Tunisian male soccer players $(24.34 \pm 5.55$ years, $70.42 \pm 7.9 \mathrm{~kg}$ and $1.76 \pm 0.06 \mathrm{~cm}$ ) belonging to the Tunisian Soccer League First Division. Participation in this study was voluntary, anonymous and confidential.

\section{Burnout dimensions assessment}

We have evaluated the burnout in the Tunisian male soccer players by referring to the Maslach Burnout Inventory (MBI) questionnaire developed by Maslach (1996). This test evaluates the burnout through its three components such as emotional exhaustion (EE), depersonalization (DEP) and the reduced personal accomplishment (RPA). The questionnaire consists of 22 items. Subscales of burnout respond to the feelings of emotional exhaustion, deshumanization and reduce personal accomplishment. Indeed, each burnout dimension is the result of the addition of scores in a series of data items (Maslach et al., 1996). Each item is assessed according to the scale of Likert scale graduated from 0 to 6 (Likert, 1932). Thus, social-professional factors as 'Player team integration', 'Player coach relationship', 'Player age', 'Player marital status', 'Player material conditions', 'Player seniority' and 'Player position' were considered in our study.

\section{Maslach questionnaire validation}

Before the start of the actual study, a preliminary test was carried out on sixty soccer players fairly choose from the three afore mentioned teams; this to test the psychometric quality of the Maslach questionnaire used to ensure that it is understandable and is also adapted to the Tunisian soccer players' context. Thus, a confirmatory factor analysis (CFA) was performed (Kaiser, 1958).

\section{Data analysis}

The data were analysed by the SAS (Statistical Analysis System) to estimate the contribution part of regressors such as 'Player team integration', 'Player coach relationship', 'Player age', 'Player marital status', 'Player material conditions', 'Player seniority' and 'Player position' in the explanation of burnout syndrome of the soccer players through its three components, i.e. emotional exhaustion, the deshumanization of the relationship and the reduced personal accomplishment. We specify that the variables to explain that the burnout components are quantitative. However, the explanatory variables are qualitative, i.e. dichotomous or categorical. To do this, we conducted a regression analysis by the ANOVA procedure of the SAS library (SAS Institute, 1984). This method can explain the part of the contribution of regressors in explaining of the burnout variance. However, it does not specify the sign and magnitude of the influence of independent variables.

\section{Results}

The psychometric test has been validated with sixty soccer players of the Tunisian Soccer League First Division. The internal consistencies, Cronbach's alpha, were $0.69,0.74$ and 0.71 respectively for emotional exhaustion, depersonalization and reduced personal accomplishment.

The regression analyses for the three components of burnout syndrome in Tunisian male soccer players such as the EE, the DEP and the RPA are shown in table 1. They indicate that the three models are significant at the same probability level $(\operatorname{Pr} \leq 0.001)$. $\mathrm{R}^{2}$, which inform on the contribution parts of the predictors in explaining the variance of each of the three burnout components are respectively in the range of $0.67,0.63$ and 0.66 .

Table 1 specifies the contribution part, expressed as a variance, of each source-social-professional in the explanation of each burnout dimension in Tunisian soccer players and the respective significance levels. The contribution parts of the social-professional factors in the prediction of burnout dimensions are variable. Thus, the factors such as 'Player team integration', 'Player coach relationship', 'Player age', 'Player material conditions' and 'Player seniority' best explain the three dimensions and therefore the burnout problems of Tunisian male soccer players. 
Table 1. Variances and probability levels, according to the source of variation, involved in the prediction of the emotional exhaustion, deshumanization and reduced personal accomplishment components of burnout syndrome in Tunisian male soccer players.

\begin{tabular}{|c|c|c|c|c|}
\hline Sources of variation & Means square & CPTV (\%) & $\mathbf{F}$ & $\mathbf{P r} \geq \mathbf{F}$ \\
\hline & \multicolumn{4}{|c|}{$\begin{array}{l}\text { Emotional exhaustion (EE) } \\
\qquad\left(\operatorname{Pr} \leq 0.001 ; \mathrm{R}^{2}=0.67\right)\end{array}$} \\
\hline \multicolumn{5}{|l|}{ Regressors } \\
\hline Player team integration & 1564 & 11 & 19.65 & 0.0001 \\
\hline Player coach relationship & 1987 & 14 & 21.54 & 0.0001 \\
\hline Player age & 2722 & 19 & 24.26 & 0.0001 \\
\hline Player seniority & 3421 & 24 & 32.11 & 0.0001 \\
\hline Player material condition & 4561 & 32 & 46.31 & 0.0001 \\
\hline Residual & 102 & - & - & - \\
\hline & \multicolumn{4}{|c|}{$\begin{array}{l}\text { Depersonalization (DEP) } \\
\qquad\left(\operatorname{Pr} \leq 0.001 ; \mathrm{R}^{2}=0.63\right)\end{array}$} \\
\hline Player team integration & 1997 & 15 & 26.75 & 0.0001 \\
\hline Player coach relationship & 2304 & 18 & 29.29 & 0.0001 \\
\hline Player age & 2453 & 19 & 36.61 & 0.0001 \\
\hline Player seniority & 2912 & 22 & 32.17 & 0.0001 \\
\hline Player material condition & 3445 & 26 & 42.87 & 0.0001 \\
\hline \multirow[t]{2}{*}{ Residual } & 167 & - & - & - \\
\hline & \multicolumn{4}{|c|}{$\begin{array}{l}\text { Reduced Personal Accomplishment (RPA) } \\
\qquad\left(\operatorname{Pr} \leq 0.001 ; \mathrm{R}^{2}=0.66\right)\end{array}$} \\
\hline Player team integration & 1859 & 13 & 23.01 & 0.0001 \\
\hline Player coach relationship & 2406 & 17 & 22.89 & 0.0001 \\
\hline Player age & 2789 & 20 & 27.89 & 0.0001 \\
\hline Player seniority & 3112 & 22 & 38.53 & 0.0001 \\
\hline Player material condition & 3945 & 28 & 43.39 & 0.0001 \\
\hline Residual & 98 & - & - & - \\
\hline
\end{tabular}

CPVT: Contribution part to the total variance

\section{Discussion}

Raedeke (2004) defines sports burnout as a chronicle response to stress. According to Hill et al. (2008), the scarcity of research on burnout in sports is one the great hindrances to the understanding of this phenomenon, which affects athletes and coaches in high performance tasks in the sports environment. Burnout syndrome is typically characterised by long-term psychological and emotional exhaustion that is accompanied by feelings of depersonalisation and a decreased capacity to manage work requirements (Maslach, 2011).

Our study evaluated the sport burnout levels in Tunisian male soccer players belonging to the Tunisian Soccer League First Division. It showed that the Tunisian soccer players are affected by the burnout syndrome with various levels according to the different social-professional factors such as 'Player team integration', 'Player coach relationship', 'Player age', 'Player material conditions' and 'Player seniority'. These factors appear to be slightly different from those reported in other study carried out in United Kingdom on professional players of the first soccer division that which specified that 'Player age', 'Player education level', 'Player physical condition', 'Player marital status', 'Player position' and 'Player seniority' are the main factors triggering burnout (Tabei et al., 2012). These differences could be attributed to the socio-economic phenomena countries (Hoffmann et al., 2002).

The factors such as 'Player team integration', 'Player coach relationship', 'Player age', 'Player material conditions' and 'Player seniority' were in our study at the origin of the expression of the emotional exhaustion, the deshumanization and the reduced personal accomplishment in Tunisian soccer players which constitute the three dimensions of burnout syndrome. Genoud et al. (2009) reported that the stressors always act primarily on emotional exhaustion which in turn leads to the other components of burnout. This is how he sees himself exposed to burnout syndrome, a form of stress gathering, distance, detachment and coldness in interpersonal relationships, and an intense feeling of emotional resources depletion and a strong sense of acting and reacting (Santinello, 1990; Schaufeli and Enzmann, 1998).

In conclusion, our study showed that the Tunisian male soccer players of the Tunisian Soccer League First Division suffer from burnout syndrome and the predictors such as 'Player coach relationship', 'Player age', 'Player material conditions', 'Player seniority' are the major stressogenes factors. The research on burnout in the area of sports is very limited. Only recently has become an area of research. Findings of the present study show that Tunisian male soccer players experienced relatively different burnout levels. Further research on burnout and playing is necessary in order to identify the factors that may cause this syndrome. Longitudinal studies would provide useful information about the development of successive phases of burnout among athletes. 
[1]. Ahola K., Honkonen T., Isometsa E. 2005. The relationship between job-related burnout and depressive disorders results from the Finnich Health 2000 Study. Journal of Affective Disorders, 88: 55-62.

[2]. Freudenberger HJ. 1974. Staff burnout. Journal of Social Issues, 30: 159-65.

[3]. Canouï P. 2001. Le syndrome d'épuisement professionnel des soignants. De l'analyse du burnout aux réponses. 2ème édition. Paris: Masson.

[4]. Dunning E. 1999. The development of soccer as a world game. Sport Matters: Sociological Studies of Sport, Violence and Civilisation. London: Routledge. p.103.

[5]. Genoud PA., Brodard F., Reicherts M. 2009. Facteurs de stress et burnout chez les enseignants de l'école primaire. Revue européenne de psychologie appliquée, 59: 37-45.

[6]. Gumusdag H. , Bastik C., Yamaner F., Kartal A., Unlu C. 2013. Burnout in professional soccer players: the role of aggression and anxiety. IIB Inter. Refereed Academic Social Sciences Journal, 4: 10-19.

[7]. Hentati A., Slimani M., Bouazizi M., Ben Amar I., Chéour F. 2014. Social-professional antecedents and prevalence of burnout syndrome in Tunisian male kick boxers. IOSR Journal of Humanities and Social Science, 19: 35-38.

[8]. Hill AP., Hall HK., Appleton PR., Kozub SA. 2008. Perfectionism and burnout in junior elite soccer players: The mediating influence of unconditional self-acceptance. Psychology of Sport and Exercise, 9: 630-644.

[9]. Hoffmann R., Ging LC., Ramasamy B. 2002. The socio-economic determinants of international soccer performance. Journal of Applied Economics, 2: 253-272.

[10]. Kaiser H. 1958. The varimax criterion for analytic rotation of factors. Psychometrika. 23: 187-200

[11]. Laes T., Laes T. 2001. Career burnout and its relationship to couple burnout in Finland: A pilot study. Paper presented in a symposium entitled The Relationship between Career and Couple Burnout: A Cross-Cultural Perspective held at the Annual Convention of The American Psychological Association, San Francisco, California.

[12]. Likert R., 1932. Atechnique for th measurement of attitudes. Archives of Psychology, 140: 1-55.

[13]. Guttman A. 1993. The Diffusion of Sports and the Problem of Cultural Imperialism. In Eric Dunning, Joseph A. Maguire, Robert E. Pearton. The Sports Process: A Comparative and Developmental Approach. Champaign: Human Kinetics. p.129.

[14]. Maslach C., Jackson SE., Leiter MP. 1996. Maslach Burnout Inventory Manual (3rd ed.). Palo Alto, CA: Consulting Psychologist Press.

[15]. Maslach C., Schaufeli WB. 1993. Historical and conceptual development of burnout. In: Schaufeli WB, Maslach C, Marck T, editors. Professional burnout: recent developments in the theory and research. Washington: Taylor \& Francis, 1-16.

[16]. Maslach C., Schaefeli WB., Leiter M. 2001. Job burnout. Annual Review of Psychology, 5: 397-422.

[17]. Maslach C. 2011. Burnout and engagement in the workplace: new perspectives. The European Health Psychologist, 13:44-47.

[18]. Maslach C. 1982. Burnout: The cost of caring. Englewood Cliffs, NJ: Prentice-Hall.

[19]. Maslach C., Schanfeli WB., Leiter MP. 2001. Job Burnout, Annual Review of Psychology, 52: 397-422

[20]. Miller TW., Vaughn MP., Miller JM. 1990. Clinical issues and treatment strategies in stress orientated athletes. Sports Medicine, 9: 370-379.

[21]. Pines AM. 1993. Burnout: An existential perspective. In W. Schaufeli, C. Maslach, \& T. Marek (Eds.), Professional burnout: Developments in Theory and Research. Pp. 33-52. Washington, DC: Taylor \& Francis.

[22]. Pines AM., Aronson E. 1988. Career burnout: Causes and cures. New York: Free Press.

[23]. Pines AM., Aronson E., Kafry D. 1981. Burnout: From tedium to personal growth. New York: The Free Press.

[24]. Pines AM., Nunes R. 2003. The relationship between career and couple burnout: Implications for career and couple counselling. Journal of Employment Counselling, 40: 50-64.

[25]. Raedeke TD. 2004. Coach Commitment and Burnout: A One-Year Follow-Up. Journal of Applied Sport Psychology, 16: 333-349.

[26]. Santinello M. 1990. Le syndrome de burnout. Pordenone : Erip Editrice.

[27]. SAS Institute. 1984. SAS/STAT User's Guide, ver. 6, vol. 2, 4th ed. SAS Institute, Cary, N.C.

[28]. Schaufeli WB., Enzmann D. 1998. The burnout companion to research and practice: a critical analysis. London: Taylor and Francis.

[29]. Tabei Y., Fletcher D., Goodger K. 2012. The relationship between organizational stressors and athlete burnout in soccer players. Journal of Clinical Sport Psychology, 6: 146-165. 